\title{
Increasing customer loyalty: the impact of corporate social responsibility and corporate image
}

\section{Corporate social responsibility (CSR)}

It only seems like yesterday when CSR and business success were deemed mutually exclusive. How times have changed. Organizations now realize that being a good citizen can prove hugely beneficial all round. Author Peter Robinson succinctly captured the shift in perception when claiming ethics to be the "new competitive environment".

Despite the importance attached to CSR, a universal definition remains elusive. This can be largely attributed to the fact that the concept has scope to mean different things to different people in different circumstances. Notwithstanding this, all firms engaging with CSR are essentially pledging to conduct their business in ways that protect the interests of current and future generations.

The number of elements in CSR models proposed is subject to some variation. However, fundamental to most are economic, legal and ethical responsibilities. Consumer belief that firms have a moral obligation to behave in certain ways makes the latter particularly significant.

Addressing the needs of the various internal and external stakeholders is frequently a key part of such expectations. This might include a focus on issues like employee rights, health and safety in the workplace, product quality and safety, charitable work, education activities and environmental conservation.

\section{Customer loyalty}

Efforts in these and other areas often prove worthwhile though. Evidence shows that CSR can be more effective than advertising when it comes to attracting interest from consumers. Perhaps of even greater worth is its potential to enhance customer loyalty. This effect emerges as a result of "generalized reciprocity" whereby customers reward an organization for the indirect benefits provided to them when its CSR activities positively impact on their society.

Now few people will doubt the importance of customer loyalty to business organizations. Loyal customers boost a firm financially through their willingness to:

- spend more per transaction;

- make frequent purchases;

- resist the marketing efforts of rivals; and

- provide positive word-of-mouth (WOM) recommendations to significant others.

It is widely acknowledged that loyalty becomes most powerful when it is comprised of both behavioural and attitudinal components. The blend of repeat purchase behavior and emotional attachment to the company and its brands helps generate loyalty that is trobust and enduring.

Hospitality is one industry where customer loyalty is especially potent. Statistics reveal that WOM occurs to an extent that the impact on profits is often considerable. Tourism is a booming sector in which hotels are playing an increasingly major part. Hotels provide employment and other economic benefits to the communities in which they operate. Their presence is not wholly embraced though. Any economic contribution is

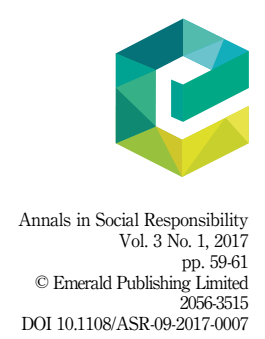


ASR

3,1

tempered by their capacity to, for instance, pollute the local environment and erode cultural values.

But many operators use CSR as an effective mechanism for countering such negativities. Damage limitation exercises might include recycling, use of organic products, contributions to local charities and support for community projects.

\section{Corporate image and its significance}

Research indicates that the impact of CSR on customer loyalty can be direct or indirect in nature. A range of different mediators have been identified including customer satisfaction, consumer identification with the firm, trust and brand image. Some of these variables appear to be influential with regard to hotel companies. However, research in that context is limited. It is also noteworthy that the few studies to be conducted thus far have ignored corporate image as a potential mediator. This is somewhat surprising given that corporate image reflects the sum of customer perceptions, experiences and knowledge associated with a firm and:

- is perceived as important within the hospitality sector;

- can be enhanced by CSR activities; and

- creates a favourable impression of the organization on those who view it positively.

The relationship between CSR and customer loyalty is of particular interest among independent hotel firms in Istanbul. Such operators account for around 60 per cent of all hotels in Turkey, where Istanbul is the second most popular tourist destination. Compared to hotel chains, independents:

- invariably have fewer resources at their disposal;

- will often have to be somewhat selective about which CSR activities to engage in;

- are likely to be better aware of local community requirements; and

- might be positioned to respond more swiftly as decision making is a less complicated process.

Optimizing the impact of CSR on customer loyalty should therefore be high on the agenda of these independent hotels. A focus on sustainable development offers a route towards achieving this objective. Economic, society and environmental dimensions are incorporated within an approach which is ideal for addressing issues pertinent to the tourism industry. Hotels might thus put considerable emphasis on activities that benefit all stakeholders financially, safeguard local culture and architecture and preserve natural resources.

\section{Using CSR activities to enhance corporate image and customer loyalty}

A survey of clients staying at independent hotels in Istanbul confirms that CSR positively affects customer loyalty and corporate image. It likewise reveals a similar connection between corporate image and customer loyalty. Another key finding from this survey is that corporate image can mediate the CSR-customer loyalty relationship. This evidently produces the strongest impact of CSR on loyalty that is also highly significant.

Independent hotels in Istanbul seemingly engage in modest amounts of CSR activities. That they concentrate largely on the economic dimension suggests that human and financial resources are indeed limited. It may also signify that CSR among these operators is yet to be fully developed.

Based on indications here, hotels should seek to: 
- increase their efforts in respect of the social and environmental dimensions of CSR; and

- enhance corporate image by exploiting various communication channels at their disposal to inform customers of these CSR activities.

Impact of CSR and corporate image

Using advertising to promote itself as socially responsible enables a company to create positive perceptions in consumer minds. This helps strengthen corporate image so that increased customer loyalty and firm competitiveness become likelier as a result.

Additional variables such as hotel location and the type and nationality of customers might further influence how CSR relates to customer loyalty.

\section{Comment}

The review is based on: "How does corporate social responsibility create customer loyalty? The role of corporate image" by Mert Gürlek, Ertugrul Düzgün and Selma Meydan Uygur, published in Social Responsibility Journal. Firms seeking to enhance customer loyalty can do so by using corporate social responsibility (CSR) as a means of creating a favorable corporate image. This can be better achieved if companies adopt a sustainable development approach and address social and environmental dimensions as well as the economic one. The authors also advocate the use of relevant communication channels to inform customers of CSR activities and accordingly help generate positive perceptions of the firm among them.

Graham Cole

\section{Reference}

Gürlek, M., Düzgün, E. and Meydan Uygur, S. (2017), "How does corporate social responsibility create customer loyalty? The role of corporate image”, Social Responsibility Journal, Vol. 13 No. 3, pp. 409-427, doi: 10.1108/SRJ-10-2016-0177. 